\title{
Measuring 3D Velocity Vectors using the Transverse Oscillation Method
}

\author{
Pihl, Michael Johannes; Jensen, Jørgen Arendt
}

Published in:

Proceedings of IEEE International Ultrasonics Symposium

Link to article, DOI:

10.1109/ULTSYM.2012.0472

Publication date:

2012

Document Version

Early version, also known as pre-print

Link back to DTU Orbit

Citation (APA):

Pihl, M. J., \& Jensen, J. A. (2012). Measuring 3D Velocity Vectors using the Transverse Oscillation Method. In Proceedings of IEEE International Ultrasonics Symposium (pp. 1881-1885). IEEE.

https://doi.org/10.1109/ULTSYM.2012.0472

\section{General rights}

Copyright and moral rights for the publications made accessible in the public portal are retained by the authors and/or other copyright owners and it is a condition of accessing publications that users recognise and abide by the legal requirements associated with these rights.

- Users may download and print one copy of any publication from the public portal for the purpose of private study or research.

- You may not further distribute the material or use it for any profit-making activity or commercial gain

- You may freely distribute the URL identifying the publication in the public portal 
Paper presented at the IEEE International Ultrasonics Symposium, Dresden, Germany, 2012:

\section{Measuring 3D Velocity Vectors using the Transverse Oscillation Method}

Michael Johannes Pihl and Jørgen Arendt Jensen

Center for Fast Ultrasound Imaging,

Biomedical Engineering group, Department of Electrical Engineering, Bldg. 349,

Technical University of Denmark, DK-2800 Kgs. Lyngby, Denmark

To be published in Proceedings of IEEE International Ultrasonics Symposium, Dresden, Germany, 2012. 


\title{
Measuring 3D Velocity Vectors using the Transverse Oscillation Method
}

\author{
Michael Johannes Pihl and Jørgen Arendt Jensen \\ Center for Fast Ultrasound Imaging, Department of Electrical Engineering, \\ Technical University of Denmark, DK-2800 Kgs. Lyngby, Denmark
}

\begin{abstract}
Experimentally obtained estimates of threedimensional (3D) velocity vectors using the 3D Transverse Oscillation (TO) method are presented. The method employs a 2D transducer and synthesizes two double-oscillating fields in receive to obtain the axial, transverse, and elevation velocity components simultaneously. Experimental data are acquired using the ultrasound research scanner SARUS. The double-oscillating TO fields are investigated in an experimental scanning tank setup. The results demonstrate that the created fields only oscillate in the axial plus either the transverse or the elevation direction. Velocity measurements are conducted in an experimental flow-rig with steady flow in two different directions (mainly in $x$ or $y$ direction). Velocity estimates are obtained along the $z$ axis. All three velocity components $\left(v_{x}, v_{y}, v_{z}\right)$ are measured with relative biases and standard deviations (normalized to expected value) below $5 \%$ and $12 \%$, respectively. For an expected velocity magnitude of $25.2 \mathrm{~cm} / \mathrm{s}$, the method estimates $24.4 \pm 3.1 \mathrm{~cm} / \mathrm{s}$ and $25.1 \pm 1.9 \mathrm{~cm} / \mathrm{s}$ for the two directions. Under similar conditions, Field II simulations yield $25.1 \pm 1.5 \mathrm{~cm} / \mathrm{s}$ and $25.4 \pm 1.6 \mathrm{~cm} / \mathrm{s}$. The experimental results validate the results obtained through simulations and verify that the 3D TO method estimates the full 3D velocity vectors simultaneously as well as the correct velocity magnitudes.
\end{abstract}

\section{INTRODUCTION}

Ultrasonic velocity estimation has come far since the first measurements were conducted [1]. Yet, the conventional methods in commercial scanners estimate the axial velocity component only. This is the case despite the fact that studies have shown that the velocity vectors have components in all three spatial dimensions and vary as a function of time and space [2], [3], [4]. Several ultrasound methods have been proposed for measuring three-dimensional (3D) velocities over the past decades. These includes cross-beam methods [5], [6], [7], speckle [8] or feature tracking methods [9], transverse Doppler methods using the spectral broadening effect [10], [11], decorrelation based techniques [12],cross-correlation of beams [13], [14], [15], or particle imaging velocimetry [16], [17], [18]. However, the various techniques have individual limitations such as limited field of view, high computational demands, or the need for contrast agents.

The authors have suggested an approach for estimating 3D velocity vectors by means of two transverse oscillating fields, spatial quadrature sampling, and the use of a 2D phased array transducer [19], [20]. Simulation results demonstrated that the 3D Transverse Oscillation (TO) method has the ability to estimate 3D velocity vectors. This paper presents experimentally obtained $3 \mathrm{D}$ vector velocities measured in a flow-rig system using the $3 \mathrm{D}$ TO method to validate the previously reported findings. This is attained by measuring the transverse oscillating fields and by measuring 3D velocity profiles through an artificial vessel in a flow-rig system using an experimental research scanner and a 2D matrix array. To underline the validity of the previously reported simulation results, the experimentally obtained measurement results are compared with results from simulations.

To achieve the objective, the paper briefly refers to the $3 \mathrm{D}$ TO method in the next section and describes the materials and methods used in Section III. Section IV presents the measured and simulated TO fields and the corresponding spectra, and Section V presents the measured and simulated 3D velocities. The conclusion is stated in Section VI.

\section{The 3D Transverse Oscillation Method}

The 3D TO method [20] employs a Transverse Oscillation approach as suggested by Jensen and Munk [21], where Anderson [22] proposed a similar method. The 3D TO method estimates the two transverse velocity components based on two pairs of double-oscillating fields and spatial quadrature sampling by employing a $2 \mathrm{D}$ matrix array transducer. The TO fields are designed so they only oscillate in the axial and one of the two transverse directions ( $x$ or $y$ ). Thereby the velocity estimation is decoupled into the velocity components $v_{x}, v_{y}$, and $v_{z}$ [19].

The three estimated velocity components are estimated simultaneously by 5:1 parallel beamforming in receive of four TO lines and a center line for axial velocity estimation. The two sets of pairwise TO lines are beamformed with a distance of a quarter spatial wavelength. The spatial wavelengths are determined as the mean transverse wavelength, $\bar{\lambda}_{x}$, and the mean elevation wavelength, $\bar{\lambda}_{y}$, based on the TO spectra [21], [23]. After the beamforming, the velocity estimation utilizes the estimator suggested by Jensen [24]. The velocity estimation is the same for $v_{x}$ and $v_{y}$. The axial velocity component is calculated using a conventional autocorrelation estimator with RF averaging [25].

\section{MATERIALS AND Methods}

The 3D TO method requires a $2 \mathrm{D}$ transducer. A $3.5 \mathrm{MHz}$ 32x32 element 2D matrix array transducer (Vermont S.A., Tours, France) is used. The pitch is $0.3 \mathrm{~mm}$. The transducer consists of four blocks of $8 \times 32$ elements. These four blocks 


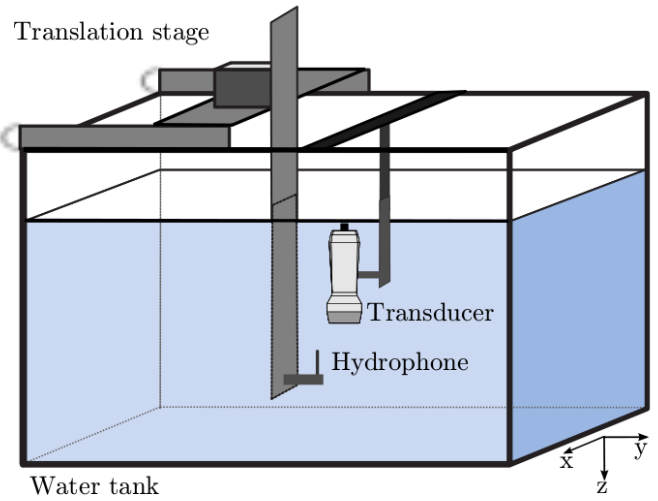

Fig. 1. The AIMS III scanning tank system (Onda, Sunnyvale, CA) with mounted 2D transducer and HGL-0400 capsule hydrophone + preamplifier (Onda, Sunnyvale, CA), which are connected to SARUS.

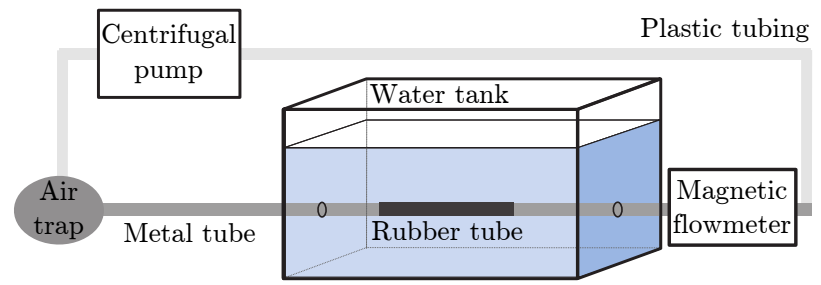

Fig. 2. The in-house flow-rig system. It is a closed loop circuit and a Cole-Parmer (Vernon Hills, IL) centrifugal pump circulates a blood-mimicking fluid (Danish Phantom Design, Frederikssund, Denmark) with a viscosity, $\mu$, of $3.9 \mathrm{mPa} \cdot \mathrm{s}$, and a density, $\rho$, of $1.0 \times 10^{3} \mathrm{~kg} / \mathrm{m}^{3}$ - A calibrated magnetic MAG1100 (Danfoss, Nordborg, Denmark) flowmeter measures the flow-rate. The internal radius is $6 \mathrm{~mm}$, and the length is long enough to ensure fully developed laminar flow, which has a parabolic flow profile. A transducer fixation device can be lowered into the tank at adjustable beam-to-flow angles.

are stacked together separated by an inactive row of elements, hence, the element layout of the transducer differs in the $x$ and the $y$ direction. At a sampling frequency of $70 \mathrm{MHz}$, data from all the 1024 active elements are acquired simultaneously through the 1024 channels on the synthetic aperture real-time ultrasound system (SARUS) [26]. Data are stored for offline processing.

The scanning tank system for pulse-echo measurements, the flow-rig system for velocity measurements, and the flow phantom setup are illustrated in Figs. 1-3, respectively. Simulations, which mimic the measurements, were performed using the ultrasound simulation program Field II [27], [28] in order to compare the measurement results with simulated results. This is performed because the physical transducer differs slightly in layout compared with the previously reported simulation results [19].

In transmit, Hanning windowed 8-cycle pulses at the center frequency were emitted with a 2D Hamming apodization. In receive, the aperture was modulated in either the $x$ or $y$ direction with two 8-element wide rectangular TO peaks. The individual channel data sampled with SARUS or obtained through the simulations were matched filtered with the timereversed excitation pulse prior to the beamforming stage. The beamforming was performed using the Beamformation

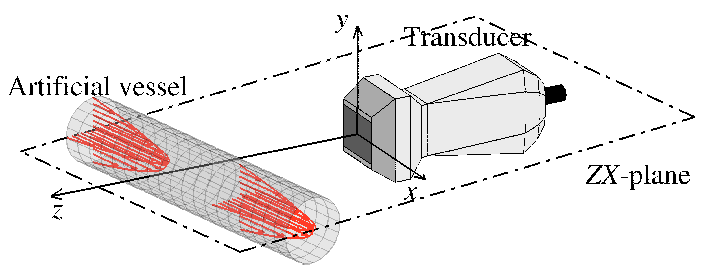

Fig. 3. Illustration of the flow phantom for measurements and simulations. The beam is steered along the $z$ axis, and the beam-to-flow angle $\phi_{z x}$ is $80^{\circ}$ and $\phi_{z y}$ is $0^{\circ}$ as one of the two cases of flow directions. The velocity profile inside the vessel is a circular-symmetric two-dimensional parabolic profile with a peak velocity, $v_{0}$, of $25.2 \mathrm{~cm} / \mathrm{s}$.

Toolbox 3 [29]. Clutter filtering is performed by subtracting the mean of the 32 emissions in an ensemble.

\section{The Transverse OsCillation Fields}

Pulse-echo measurements were performed in the scanning tank. The hydrophone was used as a point source and the transmit-receive pulse-echo field was sampled at various positions in the field. For these measurements, plane waves were emitted. To obtain the TO fields, the temporal IQ data are obtained by use of the Hilbert transform on the time-sampled signals. Then the signals from the left and right beams are combined to create the complex TO fields [23].

The TO method depends on creating two pairs of doubleoscillating fields. For the first pair, the oscillations should be in the axial and the transverse direction, but not in the elevation direction. Conversely for the second pair, the oscillations should be in the axial and the elevation direction, but not in the transverse direction. Fig. 6 shows the pulse-echo measurements of the TO fields for a specific time instance in the sampled signals. The point target was positioned at a depth of $30 \mathrm{~mm}$. Fig. $6 \mathrm{~A}$ is for the left and the right beam in the $Z X$ plane when sampling along the $x$ direction. Ideally, the right beam should overlap with the Hilbert transform of the left beam for the spatial IQ modulation to work perfectly. The same should be the case in Fig. 6D, where the samples from the two TO beams in the $Z Y$ plane were obtained sampling along the $y$ direction. Oppositely, in Fig. 6B and 6C, the left and right beam should be in phase, because in those two cases, the TO fields were sampled in the non-oscillating direction.

The measured fields exhibit the expected trends, and they can be compared with the simulated results shown in Fig. 5. The behaviour of the simulated results is more ideal, and reflects the fact, that the simulation environment is free of the system noise and the phase errors present in the measurements. Additionally, any potential misalignment in the measurements, do not occur in the simulations. Yet, the simulated as well as the measured TO fields demonstrate, that the spatial IQ approach has worked, and that the TO fields oscillate only in either the transverse or the elevation direction.

Calculating the mean transverse and elevation wavelengths based on the measured TO spectra [23] yield $8.0 \mathrm{~mm}$ and $5.4 \mathrm{~mm}$, respectively. The simulated results are $3.7 \mathrm{~mm}$ and $3.3 \mathrm{~mm}$ for $\bar{\lambda}_{x}$ and $\bar{\lambda}_{y}$, respectively. The theoretically calculated values are $3.4 \mathrm{~mm}$ and $3.0 \mathrm{~mm}$. The differences in $\lambda_{x}$ 
A

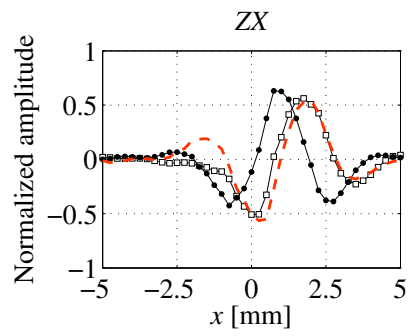

C

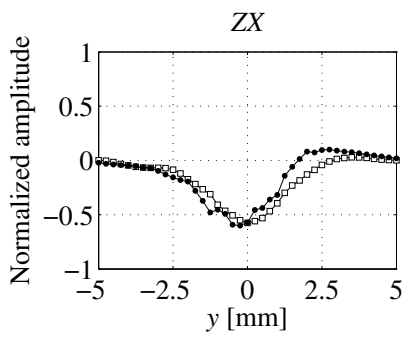

B

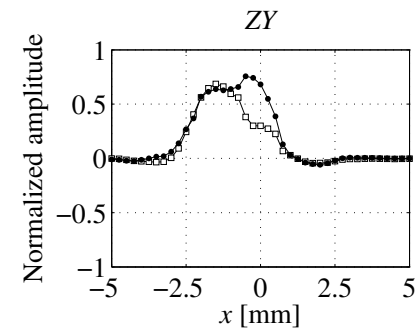

D

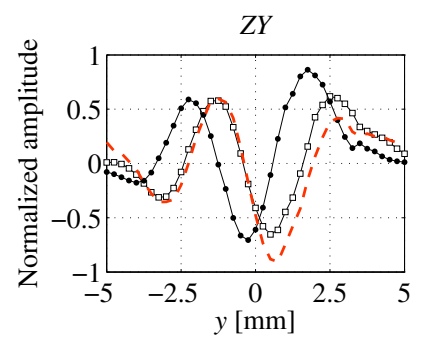

Fig. 4. Measured TO fields at a depth of $30 \mathrm{~mm}$ for a fixed time across either the transverse (A and B) or the elevation $(\mathbf{C}$ and $\mathbf{D})$. Dots $(\cdot)$ and squares $(\square)$ denote samples for the left and right beam, respectively. $\mathbf{A}$ and $\mathbf{C}$ are for the two beams in the $Z X$ plane. $\mathbf{B}$ and $\mathbf{D}$ are for the beams in the $Z Y$ plane. The dashed line is the Hilbert transform of the left beam (in $\mathbf{A}$ and $\mathbf{D}$ ).

A

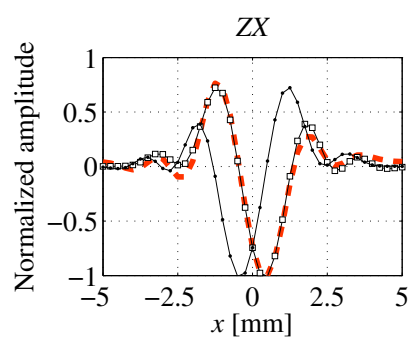

C

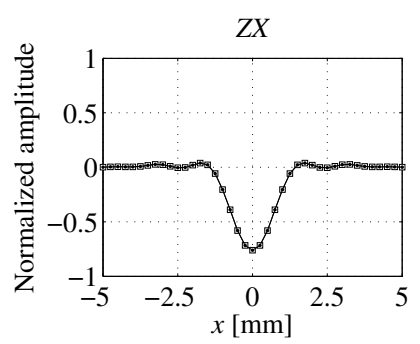

B

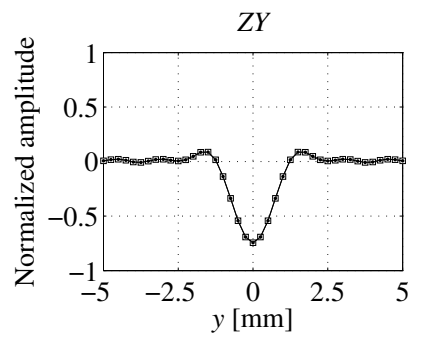

D

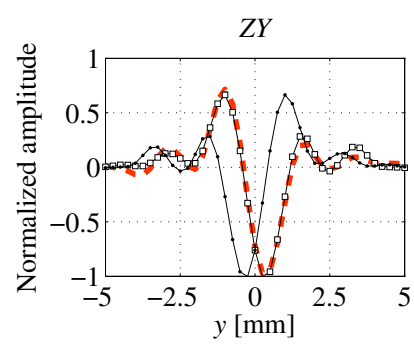

Fig. 5. Simulated TO fields at a depth of $30 \mathrm{~mm}$ for a fixed time across either the transverse (A and $\mathbf{B}$ ) or the elevation $(\mathbf{C}$ and $\mathbf{D})$ ). Dots $(\cdot)$ and squares $(\square)$ denote samples for the left and right beam, respectively. $\mathbf{A}$ and $\mathbf{C}$ are for the two beams in the $Z X$ plane. $\mathbf{B}$ and $\mathbf{D}$ are for the beams in the $Z Y$ plane. The dashed line is the Hilbert transform of the left beam (in $\mathbf{A}$ and $\mathbf{D}$ ).

and $\lambda_{y}$ are a result of the geometrical differences in the $x$ and $y$ direction. As potential misalignment, phase errors in the transducer, and system noise affect the measured TO fields. The simulated $\bar{\lambda}_{x}$ and $\bar{\lambda}_{y}$ are used in the beamforming and the velocity estimation of the flow data.

\section{3D Vector Velocity Estimation}

The results from the velocity estimation based on the experimental flow-rig measurements and flow phantom simulations are presented and discussed in the following. The flow measurements and the simulations were conducted with two different flow directions in regard to the transducer. In one case, the beam-to-flow angles in the $Z X$ plane, $\phi_{z x}$, and the $Z Y$ plane, $\phi_{z x}$, were $80^{\circ}$ and $0^{\circ}$, respectively. In the other case, $\phi_{z x}$ was $0^{\circ}$ and $\phi_{z y}$ was $80^{\circ}$. The former case is illustrated in Fig. 3.

The velocity components $v_{x}, v_{y}$, and $v_{z}$ were estimated using the $3 \mathrm{D}$ TO method and 50 velocity profiles were obtained based on 1600 emissions acquired at a rate of 600 $\mathrm{Hz}$. The mean \pm the range of one standard deviation of the 50 profiles are shown in Figs. 6 and 7. The left panels in Figs. 6 and 7 are for the flow direction expectedly confined to the $Z X$ plane, and the right panels for the flow direction in the $Z Y$ plane. The SNR was approximately $7-10 \mathrm{~dB}$ for the measurements, and a corresponding level of noise was added to the simulations, which were performed with the same parameter settings as the measurements. In all the two times six graphs in Figs. 6 and 7, the mean of the estimated velocity components follows the expected profiles and almost no bias is present. The magnitude of the standard deviations from the measurements compared with the simulations are also comparable.

A more quantitative comparison is performed by investigating the mean velocities, the expected velocities, and the bias at the center of the vessel as presented in Table I and Table II for the measured and the simulated data, respectively. The results show that the standard deviations are comparable ranging from $1.5 \mathrm{~cm} / \mathrm{s}$ to $3.3 \mathrm{~cm} / \mathrm{s}$. In the measurements, the relative standard deviation normalized to the peak velocity magnitude ranges from $8 \%$ to $12 \%$. In the simulations, it ranges from 6 to $13 \%$. Similarly, the biases from measurements and simulations are of the same size and fluctuates around 0 . The largest bias is less than $5 \%$. This demonstrates that using the mean spatial wavelengths obtained from simulations in the beamforming and the velocity estimation instead of the theoretically derived wavelengths eliminates the bias otherwise present.

With estimates of all three velocity components, it is possible to obtain the true velocity magnitude. The results for the center of the vessel are listed in Table III. The performance is comparable for simulations and measurements, and the relative standard deviation is less than $13 \%$, whereas almost no bias is present.

The results demonstrate that even with system noise, phase errors, and other transducer inaccuracies, the standard deviation of the velocity estimates is not much higher compared with the simulations where the added noise was white zeromean Gaussian noise. Additionally, it is expected that the performance will be improved in a commercial implementation, where systems usually suffer less from noise and the transducer manufacturing process is more streamlined. 

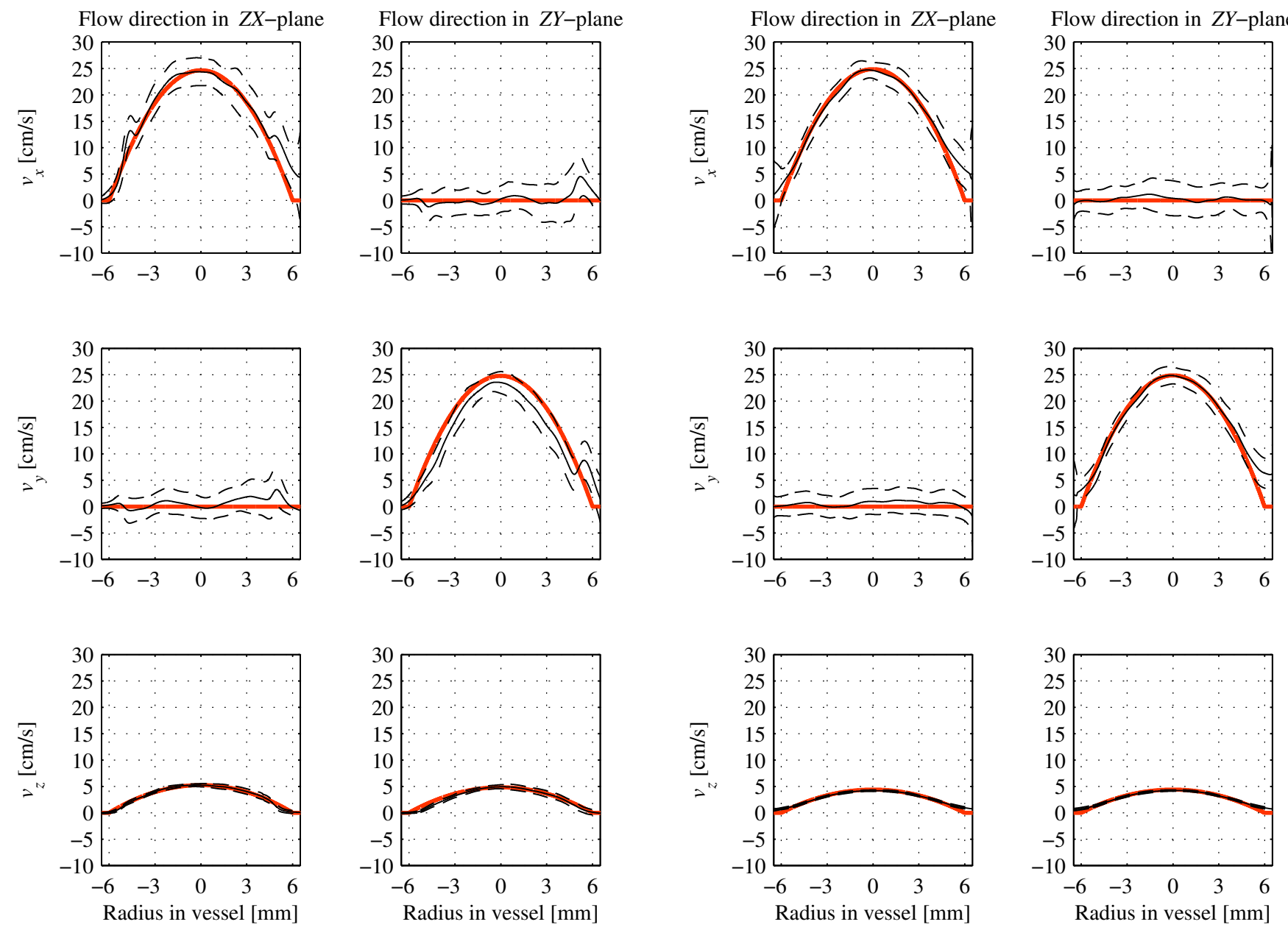

Fig. 6. Mean and standard deviation of the 50 measured velocity profiles for the three estimated velocity components. Thick lines indicate the expected velocity profile, thin lines indicate the mean of the profiles, and dashed red lines one standard deviation. The actual beam-to-flow angles were $78^{\circ}$ and $79^{\circ}$, respectively. Compare with the simulated results in Fig. 7.

TABLE I

EXPERIMENTAL RESULTS

The mean $-\overline{\mathbf{v}}-$ of the $3 \mathrm{D}$ velocity vector at the center of the vessel at 30 $\mathrm{mm}$, the expected velocity vector- $\mathbf{v}_{\exp }-$, and the resulting bias $-\mathbf{B}_{\mathbf{v}}-$ for the two cases with the flow direction confined in the $Z X$ plane or the $Z Y$ plane, respectively.

$$
\begin{gathered}
\overline{\mathbf{v}}_{\mathbf{z x}}=\left(\begin{array}{c}
\bar{v}_{x} \\
\bar{v}_{y} \\
\bar{v}_{z}
\end{array}\right)=\left(\begin{array}{c}
24.4 \\
-0.21 \\
5.22
\end{array}\right) \pm\left(\begin{array}{l}
2.6 \\
2.3 \\
0.31
\end{array}\right) \mathrm{cm} / \mathrm{s} \\
\overline{\mathbf{v}}_{\mathbf{z y}}=\left(\begin{array}{c}
\bar{v}_{x} \\
\bar{v}_{y} \\
\bar{v}_{z}
\end{array}\right)=\left(\begin{array}{c}
0.25 \\
23.5 \\
4.92
\end{array}\right) \pm\left(\begin{array}{l}
2.5 \\
2.1 \\
0.39
\end{array}\right) \mathrm{cm} / \mathrm{s} \\
\mathbf{v}_{\text {exp }, \mathbf{z x}}=\left(\begin{array}{c}
24.6 \\
0.00 \\
5.24
\end{array}\right) \mathrm{cm} / \mathrm{s} \quad \& \quad \mathbf{v}_{\text {exp }, \mathbf{s}}=\left(\begin{array}{c}
0.00 \\
24.8 \\
4.82
\end{array}\right) \mathrm{cm} / \mathrm{s} \\
\mathbf{B}_{\mathbf{v}_{\mathbf{z x}}}=\left(\begin{array}{c}
-0.30 \\
-0.21 \\
-0.023
\end{array}\right) \mathrm{cm} / \mathrm{s} \quad \& \quad \mathbf{B}_{\mathbf{v}_{\mathbf{z y}}}=\left(\begin{array}{c}
0.25 \\
-1.28 \\
0.10
\end{array}\right) \mathrm{cm} / \mathrm{s}
\end{gathered}
$$
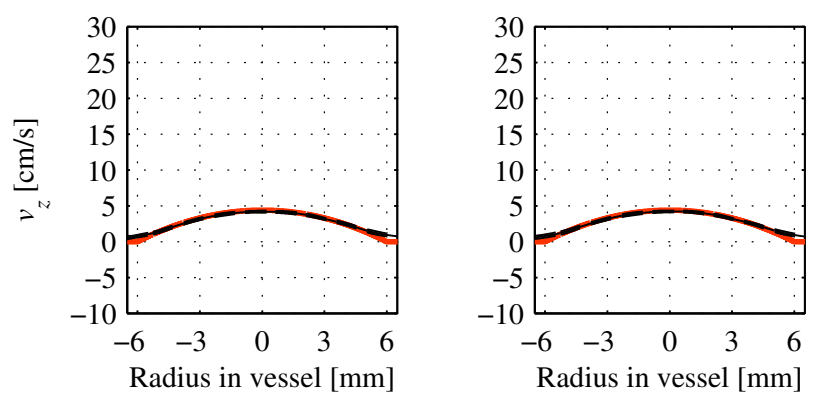

Fig. 7. Mean and standard deviation of the 50 simulated velocity profiles for the three estimated velocity components. Thick lines indicate the expected velocity profile, thin lines indicate the mean of the profiles, and dashed red lines one standard deviation. In the simulations, the beam-to-flow angles were both $80^{\circ}$ as specified. Compare with the measured results in Fig. 6 .

TABLE II

Simulated Results:

The mean $-\overline{\mathbf{v}}-$ of the $3 \mathrm{D}$ velocity vector at the center of the vessel at 30 $\mathrm{mm}$, the expected velocity vector- $\mathbf{v}_{\exp }-$, and the resulting bias- $\mathbf{B}_{\mathbf{v}}-$ for the two cases with the flow direction confined in the $Z X$ plane or the $Z Y$ plane, respectively.

$$
\begin{gathered}
\overline{\mathbf{v}}_{\mathbf{z x}}=\left(\begin{array}{c}
\bar{v}_{x} \\
\bar{v}_{y} \\
\bar{v}_{z}
\end{array}\right)=\left(\begin{array}{c}
24.6 \\
0.97 \\
4.18
\end{array}\right) \pm\left(\begin{array}{l}
1.5 \\
2.5 \\
0.14
\end{array}\right) \mathrm{cm} / \mathrm{s} \\
\overline{\mathbf{v}}_{\mathbf{z y}}=\left(\begin{array}{c}
0.38 \\
\bar{v}_{x} \\
\bar{v}_{y} \\
\bar{v}_{z}
\end{array}\right)=\left(\begin{array}{c}
3.3 \\
1.6 \\
0.14 \\
4.21
\end{array}\right) \mathrm{cm} / \mathrm{s} \\
\mathbf{v}_{\exp , \mathbf{x x}}=\left(\begin{array}{c}
24.9 \\
0.00 \\
4.38
\end{array}\right) \mathrm{cm} / \mathrm{s} \quad \& \quad \mathbf{v}_{\text {exp }, \mathbf{z y}}=\left(\begin{array}{c}
0.00 \\
24.9 \\
4.38
\end{array}\right) \mathrm{cm} / \mathrm{s} \\
\mathbf{B}_{\mathbf{v}_{\mathbf{z x}}}=\left(\begin{array}{c}
-0.24 \\
0.97 \\
-0.21
\end{array}\right) \mathrm{cm} / \mathrm{s} \quad \& \quad \mathbf{B}_{\mathbf{v}_{\mathbf{z y}}}=\left(\begin{array}{c}
0.38 \\
-0.024 \\
-0.17
\end{array}\right) \mathrm{cm} / \mathrm{s}
\end{gathered}
$$


TABLE III

Estimated Velocity Magnitudes

\begin{tabular}{lcccc}
\hline \hline \multirow{2}{*}{ Metric } & \multicolumn{2}{c}{ Measurements } & \multicolumn{2}{c}{ Simulations } \\
& $Z X$ & $Z Y$ & $Z X$ & $Z Y$ \\
\hline Expected $|\mathbf{v}|[\mathrm{cm} / \mathrm{s}]$ & 25.2 & 25.2 & 25.2 & 25.2 \\
Mean of $|\mathbf{v}|[\mathrm{cm} / \mathrm{s}]$ & $24.8 \pm 3.1$ & $25.1 \pm 1.9$ & $25.1 \pm 1.5$ & $25.4 \pm 1.6$ \\
Bias $[\mathrm{cm} / \mathrm{s}]$ & -0.36 & -0.12 & -0.13 & 0.17 \\
\hline \hline
\end{tabular}

\section{CONCLUSION}

The presented TO fields demonstrate that the spatial IQ pairs in the transverse and elevation direction are generated as required. Three-dimensional velocity estimates are obtained through experimental measurements and simulations of steady flow. The velocity profiles of $v_{x}, v_{y}$, and $v_{z}$ follow the expected profiles with a bias at the center ranging from -0.6 to $1 \mathrm{~cm} / \mathrm{s}$. Hence, using the simulated mean spatial wavelengths instead of the theoretically derived wavelengths in the beamforming and velocity estimation stages practically eliminates the bias otherwise present. The relative standard deviations were smaller than $13 \%$ for flow directions almost parallel to the transducer surface. With the same parameters and under similar conditions, the measurements and the simulations yield comparable results. Thereby, the validity of the simulation results presented here and previously reported has been verified, and it can be concluded that the 3D Transverse Oscillation method estimates the $3 \mathrm{D}$ velocity vector.

All three spatial components of the velocity are estimated simultaneous, and hence the true velocity can be obtained independent of transducer orientation or flow direction. Since the three velocity components can be obtained instantaneously, it becomes possible to measure and visualize complex flow patterns as for instance seen in the carotid artery bifurcation without employing ECG gating as used in MRI.

\section{ACKNOWLEDGMENTS}

The Danish Advanced Technology Foundation (grant 0242008-3) and BK Medical ApS, Denmark supported this work.

\section{REFERENCES}

[1] S. Satomura, "Ultrasonic Doppler method for the inspection of cardiac functions," J. Acoust. Soc. Am., vol. 29, pp. 1181-1185, 1957.

[2] P. J. Kilner, G. Z. Yang, R. H. Mohiaddin, D. N. Firmin, and D. B. Longmore, "Helical and retrograde secondary flow patterns in the aortic arch studied by three-directional magnetic resonance velocity mapping," Circulation, vol. 88, no. 5, pp. 2235 - 2247, 1993.

[3] C. A. Taylor, T. J. R. Hughes, and C. K. Zarins, "Finite element modeling of blood flow in arteries," Comput. Methods Appl. Mech. Engrg., vol. 158 , no. $1-2$, pp. $155-196,1998$.

[4] K. L. Hansen, J. Udesen, F. Gran, J. A. Jensen, and M. B. Nielsen, "In-vivo examples of complex flow patterns with a fast vector velocity method," Ultraschall in Med, vol. 30, pp. 471-476, 2009.

[5] R. E. Daigle, C. W. Miller, M. B. Histand, F. D. McLeod, and D. E. Hokanson, "Nontraumatic aortic blood flow sensing by use of an ultrasonic esophageal probe," J. Applied Phys., vol. 38, pp. 1153-1160, 1975.

[6] M. D. Fox and W. M. Gardiner, "Three-dimensional Doppler velocimetry of flow jets," IEEE Trans. Biomed. Eng., vol. 35, pp. 834-841, 1988.

[7] B. Dunmire, K. W. Beach, K.-H. Labs., M. Plett, and D. E. Strandness, "Cross-beam vector Doppler ultrasound for angle independent velocity measurements," Ultrasound Med. Biol., vol. 26, pp. 1213-1235, 2000.
[8] L. N. Bohs, B. J. Geiman, M. E. Anderson, S. C. Gebhart, and G. E. Trahey, "Speckle tracking for multi-dimensional flow estimation," Ultrasonics, vol. 38, pp. 369-375, 2000.

[9] A. A. Morsy and O. T. von Ramm, "FLASH correlation: A new method for 3-D ultrasound tissue motion tracking and blood velocity estimation," IEEE Trans. Ultrason., Ferroelec., Freq. Contr., vol. 46, no. 3, pp. 728736, 1999.

[10] V. L. Newhouse, K. S. Dickerson, D. Cathignol, and J.-Y. Chapelon, "Three-dimensional vector flow estimation using two transducers and spectral width," IEEE Trans. Ultrason., Ferroelec., Freq. Contr., vol. 41, pp. 90-95, 1994.

[11] A. McArdle, V. Newhouse, and K. Beach, "Demonstration of threedimensional vector flow estimation using bandwidth and two transducers on a flow phantom," Ultrasound Med. Biol., vol. 21, no. 5, pp. 679-692, 1995.

[12] T. Tuthill, J. Rubin, and J. Fowlkes, "Three-dimensional flow vectors from rf ultrasound signals," in Proc. SPIE - Medical Imaging - Ultrasonic Imaging and Signal Processing, vol. 4687, 2002, pp. 210-217.

[13] O. Bonnefous, "Measurement of the complete (3D) velocity vector of blood flows," in Proc. IEEE Ultrason. Symp., 1988, pp. 795-799.

[14] I. Hein, "3-D flow velocity vector estimation with a triple-beam lens transducer - experimental results," IEEE Trans. Ultrason., Ferroelec., Freq. Contr., vol. 44, pp. 85-95, 1997.

[15] J. A. Jensen and S. I. Nikolov, "A method for real-time three-dimensional vector velocity imaging," in Proc. IEEE Ultrason. Symp., 2003, pp. $1582-1585$

[16] H. B. Kim, J. R. Hertzberg, and R. Shandas, "Development and validation of echo PIV," Exp. in Fluids, vol. 36, pp. 455-462, 2004.

[17] L. Liu, H. Zheng, L. Williams, F. Zhang, R. Wang, J. Hertzberg, and R. Shandas, "Development of a custom-designed echo particle image velocimetry system for multi-component hemodynamic measurements: System characterization and initial experimental results," Phys. Med. Biol., vol. 53, pp. 1397-1412, 2008.

[18] C. Poelma, J. M. Mari, N. Foin, M. Tang, R. Krams, C. G. Caro, P. D. Weinberg, and J. Westerweel, "3D flow reconstruction using ultrasound PIV," Exp. in Fluids, vol. 50, no. 4, pp. 777-785, 2011.

[19] M. J. Pihl and J. A. Jensen, "3D velocity estimation using a 2D phased array," in Proc. IEEE Ultrason. Symp., 2011, pp. 430-433.

[20] — "A method for estimation of three-dimensional velocity vectors in ultrasound," J. Acoust. Soc. Am., vol. Submitted, 2012.

[21] J. A. Jensen and P. Munk, "A New Method for Estimation of Velocity Vectors," IEEE Trans. Ultrason., Ferroelec., Freq. Contr., vol. 45, pp. 837-851, 1998

[22] M. E. Anderson, "Multi-dimensional velocity estimation with ultrasound using spatial quadrature," IEEE Trans. Ultrason., Ferroelec., Freq. Contr., vol. 45, pp. 852-861, 1998.

[23] M. J. Pihl, J. Marcher, and J. A. Jensen, "Phased array vector velocity estimation using tranverse oscillations," IEEE Trans. Ultrason., Ferroelec., Freq. Contr., vol. In press, 2012.

[24] J. A. Jensen, "A New Estimator for Vector Velocity Estimation," IEEE Trans. Ultrason., Ferroelec., Freq. Contr., vol. 48, no. 4, pp. 886-894, 2001.

[25] T. Loupas, J. T. Powers, and R. W. Gill, "An axial velocity estimator for ultrasound blood flow imaging, based on a full evaluation of the Doppler equation by means of a two-dimensional autocorrelation approach," IEEE Trans. Ultrason., Ferroelec., Freq. Contr., vol. 42, pp. 672-688, 1995.

[26] J. A. Jensen, H. Holten-Lund, R. T. Nielson, B. G. Tomov, M. B. Stuart, S. I. Nikolov, M. Hansen, and U. D. Larsen, "Performance of SARUS: A Synthetic Aperture Real-time Ultrasound System," in Proc. IEEE Ultrason. Symp., Oct. 2010, pp. 305-309.

[27] J. A. Jensen, "Field: A Program for Simulating Ultrasound Systems," Med. Biol. Eng. Comp., vol. 10th Nordic-Baltic Conference on Biomedical Imaging, Vol. 4, Supplement 1, Part 1, pp. 351-353, 1996.

[28] J. A. Jensen and N. B. Svendsen, "Calculation of Pressure Fields from Arbitrarily Shaped, Apodized, and Excited Ultrasound Transducers," IEEE Trans. Ultrason., Ferroelec., Freq. Contr., vol. 39, pp. 262-267, 1992.

[29] J. M. Hansen, M. C. Hemmsen, and J. A. Jensen, "An object-oriented multi-threaded software beam formation toolbox," in Proc. SPIE Medical Imaging - Ultrasonic Imaging and Signal Processing, vol. 7968, 2011, p. 79680Y. 